\title{
In Memoriam: Edmond Antony Murphy, MD
}

Edmond Antony (Tony) Murphy, MD, a pioneer in the field of medical genetics and long-term collaborator of Victor McKusick's, a man with a keen interest in the philosophy of medicine and a member of the editorial staff of Theoretical Medicine and Bioethics for many years, passed away on January 12, 2009, in Barcelona, where he had lived with his niece and nephew since his retirement from Johns Hopkins University School of Medicine in 1994. He was 83 years old.

Murphy was a biostatistician with broad interests in medical theory and epistemology. I fondly remember, as a house officer at Hopkins, the pleasure of having conversations with him in which we took great delight in the suspicion that we were the only two people in the institution who could actually mention Wittgenstein and medicine in the same sentence. He was a man of grace and wit, and an accomplished classical guitarist.

He was born in Wales, and received his MD from the University of Belfast. He spent most of his career at Johns Hopkins, beginning with a post-doctoral fellowship in 1956. He contributed frequently to Theoretical Medicine and Bioethics, publishing his first article with the journal in volume 2, "The Pursuit of the Minor Premise: A Commentary on Normality," in 1982. He served as a member of the editorial board from 1982 to 1994, and was named an honorary board member by the late David Thomasma in 1998. Sadly, we will now need to remove his name from the masthead.

His books, The Logic of Medicine (1976) and Probability in Medicine (1979) are still often cited and remain among the seminal works in the philosophy of medicine. We will all miss him, but we will all continue to benefit from his erudite scholarship and his gentle wisdom.

Daniel P. Sulmasy, OFM, MD, PhD

Editor-in-Chief 